\title{
Special Issue Fall 2012: THE PEDAGOGICAL CALL
}

\begin{abstract}
Dear Reader,
As main editor, I would like to present the current special issue titled "The Pedagogical Call." I extend a warm welcome to the two guest editors, Dr. Andrew Foran and Professor Francine Hultgren, and recognition for a scholarly effort that is greatly appreciated. I would also like to thank the reviewers of this special issue, the proof reader, Alanna MacLellan-Mansell, and of course the authors, without whom this current collection of excellent phenomenological papers would not be possible.
\end{abstract}

Tone Saevi

Phenomenology \& Practice

Andrew Foran, St. Francis Xavier University, Antigonish, Nova Scotia

Email:aforan@stfx.ca

Francine Hultgren, University of Maryland, College Park, Maryland Email:fh@umd.edu

Jan van den Berg (1961) claimed that past manuscripts and the great authors made no mention of the relationship between the young and old-a lack of interest in what should concern all of us-pedagogy (p. 20). As guest editors for this Special issue, we wonder if van den Berg would be content with current scholarship, phenomenological or not, that brings the focus of the child, or the teaching relationship to the fore. As we finalized this issue, we paused to question the degree of pedagogical significance this collection of articles represents, and we are both resigned to the thoughts that van den Berg would have been more than pleased with the depth, range, and quality of phenomenological discussions that answered the pedagogic call for papers from months ago. In the work, The Changing Nature of Man, van den Berg (1961) provides an overview of pedagogical discussions that draw on Montaigne, Locke, Rousseau, Théodore Agrippa d'Aubigné, Pascal, and other scholars examining human existence-life or living with others. But near the end of the discourse, van den Berg reminds us that our society is one of adults, and "consequently ... still put[s] obstacles in the way of those growing up" (p. 108), and it is this very "adult society" that holds the reigns of "granting permissions" for the futures of youth and students.

What does this mean for those of us interested in the pedagogical relationship in current times? How does this notion of obstacles alter the relation between adult-child, teacher-student? Thus the significance of this issue is akin to Aoki's (1988) 
phenomenological position that generated meanings are understandings "constructed actively by those who dwell within the situation" (p. 411), and it is evident that the authors in this Special issue have so dwelled! In seeking out unique views, Aoki (1996) reminds us of the importance of being able to linger, reflect, and dwell. Aoki captures the pedagogical significance for us in the following:

Bridges abound-small bridges, long bridges ... moving goods and people. Today, we revel in the remarkable speed, lifelines we call them, and give thanks to all these bridges ... for helping us to move from one place to another, the speedier the better, the less time wasted the better. But if I go to an Oriental garden, I am likely to come upon a bridge, aesthetically designed, with decorative railings, pleasing to the eyes ... But on this bridge, we are in no hurry to cross over; in fact, such bridges lure us to linger ... They are dwelling places for people. (p. 10)

With this in mind, we too lingered with the submissions so kindly offered; we took time to dwell on the bridge they provided, the inside world of the relational: school, teachers, students, children ever aware of the pressures of the changing outside world of teaching. For Aoki (1990), the pedagogical relationship becomes an opportunity in which the "educator and the educated are allowed to dwell in a present that embraces past experiences and is open to possibilities yet to be" (p. 114); hence, respecting the pedagogical direction as laid out by van den Berg and many others before and after him. The authors in this Special issue have engaged in what Aoki (see Pinar \& Irwin, 2005) refers to as videre (to see), as part of the "insights" that contribute to an illuminated understanding (p. 373) for teachers and adults entrusted with students and children, bringing the individual, and the unique into pedagogical focus. But not to be forgotten as a metaphor for knowing and understanding is also sonare (to hear). The sounds of pedagogy, then, "like the ring of a temple bell, echo and reecho" the relational elements of what connects us to the lives of those in which we are in pedagogical connection.

Augustine (354-430 CE) understood pedagogical practice as the adults' response to "the call" of children and young persons (1995). Otto F. Bollnow, pedagogue and philosopher in the European pedagogical tradition, sees Augustine's pedagogical metaphor as the basic intentional quality that should characterize the relation between adult and child. Bollnow (1989) says,

Human development cannot be externally forced on the child; rather, there must be something present in the child which is oriented toward development and which asks for the help. This means that it is in the nature of the child to want to grow. (p. 24)

But what is expected of the adult in this relationship? As demonstrated by van den Berg, this question has been asked throughout the ages: how does the adult nurture, guide, or allow for this growth? Should we intervene, answer the call, and hope our response was appropriate? Should we patiently observe, with no interference, and allow nature to take the course in child rearing? Or do we arrange our responses so they are uniform, rigid, explicit, and determined on a structured program of best practices that can allow us to 
manage the child (regardless of the agenda). Pedagogically, and in our view, the impetus for growth, or rather Bildung, is not merely something guaranteed through effective or expert technique, but rather is a relational and personal educational practice between the younger and the older generation. Both Bollnow and Klaus Mollenhauer, another contributor to the European pedagogical tradition, emphasize that the adult responsibility in pedagogical situations is to cultivate an attitude or disposition (Mollenhauer in press, pp. $101^{*}$ ) that is sensitive and receptive to the often unarticulated call of the child (Friesen \& Saevi 2010, p. 134). Yet, today's focus on efficiency, results and competition in education strains the relation between adults and young people, and the pedagogical relation is under pressure in schools, homes, and societies. Regardless, Saevi and Foran, in Seeing Pedagogically Telling Phenomenologically have interrupted the daily interactions of teachers and students by asking adults to consider what they see in child encounters, all the while recognizing that maintaining a pedagogical stance in today's system of education is a struggle.

For this special issue, Saevi also provides a sensitive review of Friesen's translation of Mollenhauer's Forgotten Connections, by asking why Mollenhauer matters. This question, rooted in an exploration of pedagogical practice is as important today as it was in Augustine's and van den Berg's time. Thankfully, other contemporary scholars of pedagogy, too, have answered this call by sharing phenomenological papers that explore the pedagogical call, all contributing to an enactive, emotive, descriptive, and experiential inquiry to balance the disturbing educative trends that many teachers and educators of all disciplines face in North America and now in Europe.

Biesta explores the tension when pedagogy is squeezed out for practices that preference the technical/rational educative approaches-teacher as manager not pedagogue. In his article, on Giving Teaching Back to Education, Biesta positions his discussion with the following:

What I have in mind here is not the actual disappearance of teaching and the teacher, but the disappearance-or at least the erosion-of a certain understanding of teaching and the teacher, an understanding in which it can be acknowledged, to put it briefly, that teachers are there to teach. Putting it this way does, however, raise a further difficulty because of the fact that in recent years the argument that teachers should teach has been made most vociferously from conservative sides in an attempt to restore what might perhaps best be characterised as an authoritarian conception of teaching.

Biesta exposes the contemporary trend that "teaching is, and ultimately should be, a matter of control" leaving us to dwell in such a shallow understanding of what it means to educate the other, what it means to dwell in the relationship, and what this means for pedagogical orientations.

This special issue has addresses the complexity of what it means to be pedagogical by raising questions related to a variety of pedagogical practices across disciplines including education and the social sciences. In this issue, we are able to share experientially oriented papers that help us see, reflect on, and understand relational, ethical and educational aspects of pedagogical practice. The term pedagogy, from paidagogia, refers 
to the personal relation between child and adult, or student and teacher that is at the heart of teaching. The pedagogue accepts a special responsibility for the young person; thus pedagogical practice is an ethical practice. Pedagogical ethical qualities are intertwined with the caring, sensitivity, patience and trust we have for those for whom we feel responsible to educatively, whether they are children, adults or other than humans.

Van Manen, in The Call of Pedagogy as the Call of Contact, brings us into the heart of the pedagogical call through a sharing of the "call as contact." He engages us with his haunting pedagogical question: "How are we to act and live with children, helping them to create their human capabilities, while realizing that we are apt to do damage?" Contact, then, is anecdotally displayed as "in-touchness" with students through five modes of contact, each having certain effects and pedagogical practices. The pedagogical call grows out of the connection to the vocation of pedagogy that "animates and inspires us" (van Manen, 1991). Van Manen moves scholars to consider pedagogical practices that do just that, as the articles in this Special issue reveal.

As various dimensions of pedagogical callings are explored in these articles, a common thread is the intimate link between the teacher and student. Ayala Carabaja, in Pedagogical Hope, explores the powerful influence of hope in the responses that educators make as they engage with the children entrusted to their care. In living with children, the act of "hope-expectation" is converted into "pedagogical hope." The shift from asking, "What will become of this child or youth?" to "What could this child or youth become" and "What am I going to make possible and contribute to happening?" shows the pedagogical transformation. As Aya Carabaja proclaims: "If we approach hope's mystery with amazement, if we become familiar with its essence... we are prepared to take the path of hope to which these lived accounts of educators attest."

Smith addresses the call in Caring Caresses and the Embodiment of Good Teaching by reviving care as a pedagogical attitude. Smith, drawing on phenomenological accounts, has traced the "configuration of teaching from our earliest engagements with children to the dynamics of the university classroom." Guiding this discussion is a range of scholars from van Manen's (1991) study of "pedagogical tact," McWilliam's "education” of youth, Snowber's "curriculum of longing” for all ages, and Barreca's and Morse's "erotics of instruction" in college settings. Central to Smith's discussion is care and for us, we are left pondering how we, too, respond to care in our pedagogical encounters.

Responding to the pedagogical moment calls for a responsiveness to calls that are both articulated, as well a those that are not. Through phenomenologically-oriented vignette research, Westfall-Greiter and Schwartz, in Planning for the Unplannable: Responding to (Un)articulated Calls in the Classroom, first address what "reading a call" means. There is a confluence of "hearing" a call with that which can be sensed in "seeing" a call through gestures, postures and facial expressions. The authors exhort us to "plan for the plannable and expect the unexpected."

As the idea of "cultural heritage" articulated by Mollenhauer is explored by Friesen and Hamelock, in "Augustine, Wittgenstein, and "the Call” in Mollenhauer's Forgotten Connections: On Culture and Upbringing," the questions taken up are: "How is language actually learned, and what exactly does a person learn when they learn a language?" Through a close read of Mollenhauer's interpretation of both Augustine and Wittgenstein, the authors show an alternative provided by Mollenhauer that offers an understanding of 
"upbringing” as the starting point for life and language. Pedagogy or the pedagogical call, is shown to be "a drawing out of that which is innermost, most deeply individual and subjective - and least reduced to language and labels.” And in Mollenhauer's terms, they show that to educate children means "taking them across the boundary from the unsayable of contingent subjectivity to the realm of language, culture and convention."

Borenzweig's article, Coming to Craft and Coming of Age, positions her response to the pedagogical call by examining how the lived experiences of "[Advanced Placement] English teachers are caught in the tension between teaching a rich and engaging collegelevel introductory English course to high school students." Borenzweig asks: "What is it like to prepare students for a standardized test while simultaneously trying to engage them in meaningful experiences of literature and writing?” But she explores and teases out the richness of the pedagogical exchange between teacher and pupil. Borenzweig's article is a testament, echoed by Biesta, that our educative focus has been stuck looking fundamentally in the wrong directions. Borenzweig steps back and refocuses the pedagogical intent by saying: "Although much has been written about how to prepare the students for the exams, including how to structure the course and how to choose texts, little exists on what it is like for teachers to teach Advanced Placement English. For much of the school year, the specter of the exam looms like Catherine Earnshaw's ghost outside Lockwood's window during his first slumber party at Wuthering Heights.” In short, Borenzweig reminds of the pupil and the importance of retaining this as the primary focus in our teacherly reflections.

Fuglseth's pedagogical discussion allows us to explore the pedagogical practice in Ignoring the Child and the Call for a Good Balance by presenting "different aspects of teachers' actions seen against a phenomenological analysis of action ... in pedagogical theory as seen in the European Bildung tradition." Fuglseth explores the possibilities of "articulating a theory of teacher actions in light of Husserlian-based, critical and constitutive phenomenology of action.” Fuglseth presents phenomenological glimpses of what for many may seem a "strange action" for a teacher: the ignoring or negligence of children as a pedagogical strategy.

In a more theoretic engagement, Saeverot and Torgersen, in Education and its Borderlines: An Essay about the Nature of Education, move us to a larger sense of "call" that is found in the exploration of how a discipline issues a response to the call of research. The question they pose, "May education be thought of independently, without being reliant on other disciplines?” is threaded throughout by consideration of Hegel's "dialectic structure” in his Phenomenology of Spirit. Litt, as a co-reader of Hegel, is drawn upon to illustrate the dialectic between guidance and "letting grow" as the basic educational problem. The difference between the disciplines of education and psychology offer varying pedagogical implications for teachers to be responsive to the call of pedagogy.

Each of these articles have explicated experientially the various aspects of contemporary lived pedagogical practice with children, young persons, and students within the various practices to show phenomenologically a dimension of human development that is crucial to preserve. The call, from the child or student cannot go unanswered. Huebner (1999) traces the Latin root of vocation as a call or a summons. What is it that gets summoned in such a call? What lingers in the echoes of calling voices? To be so called is to have a sense of responsibility and obligation-to be 
answerable (Huebner, 1987), or as Caputo puts it, "to hear what is calling in the call" (1988, p. 61). Thus, we invite you to explore the following papers as you reflect on your own pedagogical encounters and hopefully they will awaken a disposition of pedagogical response.

\section{References}

Aoki, T. (1988). Toward a dialectic between the conceptual world and the lived world. InW. Pinar (Ed.), Contemporary curriculum discourses (pp. 402-416). Scottsdale, AZ: Gorsuch Scarisbrick.

Aoki, T. (1990). Themes of teaching curriculum. In J. T. Sears \& J. D. Marshall (Eds.), Teaching and thinking about curriculum: Critical inquiries (pp. 111-114). New York: Teachers College Press.

Aoki, T. (1996). Imaginaries of "East and West:" Slippery curricular signifiers in education. Proceedings of the International Adult and Continuing Education Conference (pp. 1-10). Sponsored by the Office of Research Affairs, Chung-Ang University Korea Research Foundation.

Aoki, T. (2005). Sonare and Videre: A story, three echoes and a lingering note. In W. F. Pinar \& R. Irwin (Eds.), Curriculum in a new key: The collected works of Ted T. Aoki (pp. 368-376). Mahwah, NJ: Lawrence Erlbaum.

Augustine, A. (1995) [397] Confessions. Cambridge: Cambridge University Press.

Bollnow, O. F. (1989) [1968] The pedagogical Atmosphere. Phenomenology + Pedagogy, 7, 5-63. Available online at: http://www.phenomenologyonline.com/articles/bollnow.html

Caputo, J.D. (1988). Beyond aestheticism: Derrida's responsible anarchy. Research in Phenomenology, 18, 59-73.

Friesen, N., \& Sævi, T. (2010) 'Reviving forgotten connections in North American teacher education: Klaus Mollenhauer and the pedagogical relation', Journal of Curriculum Studies, 42: 1, 123-147, First published on: 11 February 2010 (iFirst)

Huebner, D. (1999). Teaching as a vocation. In V. Hillis \& Pinar (Eds.), The lure of the Transcendent: Collected essays by Dwayne E. Huebner. Mahwah, NJ: Lawrence Erlbaum.

Mollenhauer, K. (in press). Forgotten connections: On culture and upbringing. (Translated and edited by Norm Friesen). See: http://www.culture-andupbringing.com. 
Pinar, W., \& Irwin, R. (Eds.). (2005). Curriculum in a new key: The collected works of Ted T. Aoki. Mahwah, NJ: Lawrence Erlbaum Associates.

van den Berg, J. H. (1961). The changing nature of man: Introduction to a historical psychology. New York: W. W. Norton \& Company.

van Manen, M. (1991). The tact of teaching. Albany: State University of New York Press. 